\title{
Recursos Humanos de Medicina Intensiva em Portugal na Era Pós-COVID
}

\section{Human Resources for Intensive Care Medicine in Portugal in the Post-COVID Era}

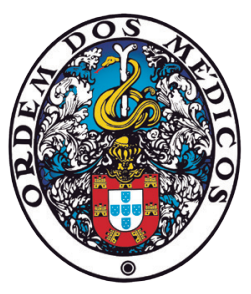

\author{
Paulo MARTINS $\square 1$ \\ Acta Med Port 2020 Sep;33(9):537-539 - https://doi.org/10.20344/amp.14351
}

Palavras-chave: COVID-19; Cuidados Intensivos; Especialização; Necessidades e Demandas de Serviços de Saúde; Padrões de Prática Médica; Portugal; Unidades de Cuidados Intensivos

Keywords: COVID-19; Critical Care; Health Services Needs and Demand; Intensive Care Units; Portugal; Practice Patterns, Physicians; Specialization

Com a epidemia de poliomielite, no início da década de 50 do século $X X$, num contexto de recursos escassos surgiu a evidência de que era possível salvar doentes em falência orgânica desde que sujeitos a atitudes e gestos adequados. Pensou-se então que se reproduzíssemos esta filosofia em espaços próprios, poderíamos obter idênticos resultados em doentes com falências orgânicas, surgindo assim os primeiros serviços de Medicina Intensiva (SMI).

Ao longo das décadas seguintes, mercê da evolução técnica da medicina, assistimos a um aumento da esperança de vida e com este, ao aumento do número de co-morbilidades dos doentes hospitalizados, motivando solicitações crescentes de internamento em medicina intensiva. Prova disso é que nos SMI europeus são ventilados anualmente 990000 a 1500000 doentes/ano e são internados por quadros sépticos 1100000 a 1400000 doentes/ano. ${ }^{1}$

Isto torna os SMI dos países desenvolvidos, responsáveis por $13,2 \%$ dos gastos hospitalares, $4,1 \%$ dos gastos nacionais e $0,74 \%$ do produto nacional bruto. ${ }^{2}$

No princípio deste século, o papel do intensivista não se confinava já às paredes dos SMI, mas era exercido muito para além destas, centrado no continuum da evolução do doente crítico que começa muito antes da chegada do doente ao SMI e se continua depois da alta do serviço. Desta forma, os intensivistas passaram a exercer actividade na sala de emergência, a integrar equipas de emergência interna nas enfermarias do hospital, a liderar a orientação de doentes nas unidades de nível II, ditas intermédias, na dependência funcional da Medicina Intensiva (MI) e a realizar consultas de follow-up, surgindo assim o conceito de circuito do doente crítico.

Isto fez aumentar a necessidade de especialistas formados na observação global, estabilização e equilíbrio de doentes graves numa perspetiva multidisciplinar.

Em Portugal, o reconhecimento da necessidade de formação específica em MI para médicos de outras especialidades foi regulada pela criação do ciclo de estudos especiais em Medicina Intensiva (despacho 276/89). ${ }^{3}$

A formação era exclusiva de seis hospitais nacionais, por isso o número de intensivistas formado era pequeno.

Só no início de século XXI, com a criação da sub-especialidade, é que a Ordem dos Médicos (OM) inicia a admissão por consenso dos intensivistas, processo que culmina em maio de 2003 com a aprovação do "Documento Orientador da Formação em Ml - critérios de idoneidade e formação" ${ }^{4}$ A partir daí a OM passava a regular toda a actividade de formação, avaliando os SMI e classificando-os por critérios de idoneidade formativa, formalizando e mantendo actualizado o documento orientador dessa formação e avaliando os formandos no fim do período formativo. Todo este percurso permitia que especialistas de outras áreas se tornassem intensivistas.

O reconhecimento da Medicina Intensiva como especialidade autónoma surge em 2015 com a renovação estatutária da OM (Lei 117/2015). ${ }^{5}$ Em 2016 é publicada a portaria $(103 / 2016)^{6}$ que cria e regula a área profissional de especialização em Medicina Intensiva, constando o conteúdo formativo de adenda ao Anexo I do Regulamento do Internato Médico, publicado na portaria 224-B/2015. ${ }^{7}$ Este passo foi sem dúvida um dos mais importantes na consolidação da Medicina Intensiva em Portugal.

Até à criação da especialidade, a formação em Ml era feita de forma irregular, dependente da boa vontade das administrações em abrir vagas para esse fim. Isto tornava o processo formativo aleatório, lento, precário, e não programado para as necessidades reais enfrentadas pelos hospitais, nem adaptado à necessária renovação de quadros decorrente das saídas por aposentação.

A especialidade irá permitir de forma regular e programada, garantir uma formação contínua de qualidade em Medicina Intensiva dotando os SMI, dos recursos humanos necessários ao crescimento que se avizinha.

Será já a partir de 2022 que sairão os primeiros especialistas de formação específica em Medicina Intensiva. Até lá, mantêm-se duas vias formativas uma com cinco anos da recém-criada especialidade e outra, clássica, com um período de tempo variável, definido pelo Colégio de Especialidade de Medicina Intensiva (CEMI), em função do currículo

1. Serviço de Medicina Intensiva. Centro Hospitalar e Universitário de Coimbra. Coimbra. Portugal.

$\triangle$ Autor correspondente: Paulo Martins. paulocoimb@gmail.com

Recebido: 16 de junho de 2020 - Aceite: 18 de junho de 2020 | Copyright @ Ordem dos Médicos 2020 
prévio do candidato.

Desde que surgiram, os SMI tem registado um aumento gradual do número de camas, mesmo em circunstâncias de redução do número geral de camas hospitalares. Este aumento de camas não é acompanhado proporcionalmente pelo aumento no número de intensivistas. Embora se desconheça a métrica que define o número ideal de intensivistas por SMI, reconhece-se que há um défice global agravado pelo envelhecimento dos médicos que aí trabalham (a média etária do quadro de muitos SMI nacionais está acima dos 52 anos).

Em Portugal o número de camas de Ml por 100000 habitantes subiu de 4,2/100 000 habitantes, ${ }^{8}$ para $6,5 /$ 100000 no censo 2020 do CEMI. ${ }^{9}$ Ainda assim, continua a ser escasso para as necessidades como comprovam as taxas de internamento superiores a $90 \%$ de muitos dos SMI nacionais.

O impacto da presença do intensivista na orientação do doente crítico melhora os resultados - reduz a taxa de mortalidade, reduz tempo de ventilação, reduz o tempo de internamento e diminui o número de falências multiorgânicas. ${ }^{10}$

Sabemos igualmente que a relação intensivista/doente crítico é determinante para garantir a qualidade da observação/tratamento dos doentes, assegurar o correcto treino de futuros intensivistas e garantir uma dinâmica assistencial estável nos SMI. ${ }^{11}$

Não existe uma fórmula ideal para o cálculo do número de intensivistas necessários para um SMI. Há fórmulas que relacionam o número de intensivistas por cama, outras estabelecem rácios por população de 100000 habitantes, outras ainda quantificam o número de intensivistas em função das tarefas a realizar de modo a garantir o funcionamento dos SMI 24 horas por dia, sete dias por semana, durante os 365 dias do ano.

Com frequência, a constituição da equipa dos SMI é calculada tendo unicamente por base a actividade assistencial ( $n^{\circ}$ camas $/ n^{\circ}$ habitantes). Contudo, tais métricas sobrestimam ou subestimam a força laboral necessária para concretizar as diversas actividades acometidas aos SMI, condicionando por vezes a resposta a situações de maior procura que ocorrem com frequência ao longo do ano.

O que deveria influenciar o cálculo do rácio intensivista/doente crítico é o conjunto de actividades necessárias à missão do SMI dentro do hospital, repartidas pela actividade assistencial ajustada à gravidade da doença, pela docência/formação de internos, pela investigação, pelos diversos gestos clínicos realizados, pela actividade no circuito do doente critico e pelas actividades de gestão e organização hospitalares. Dessa forma, o número calculado de médicos seria o que resultasse da relação entre o tempo de actividade global e o número máximo de horas anuais contratadas para o SMI. ${ }^{12}$

Actualmente, o número de especialistas de Medicina Intensiva a exercerem nos hospitais portugueses é de 282 intensivistas para um total de 669 camas (Censos 2020 do CEMI). ${ }^{9}$ Se tomarmos por referência as recomendações do documento da Rede de Referenciação de Medicina Intensiva, publicado pela Administração Central do Sistema de Saúde em 2016 que refere que "o número de médicos especialistas de Medicina Intensiva por cada unidade funcional de 8 - 12 camas deve ser, pelo menos, de seis", ${ }^{13}$ então teremos neste momento um défice de 119 intensivistas.

A prova real da existência desta lacuna é a de que numerosos serviços se servem de médicos especialistas mas não intensivistas para completar horário e em algumas circunstâncias para assegurar em pleno o funcionamento dos SMI na maioria dos dias da semana. Neste momento, temos em Portugal 110 médicos nessas circunstâncias, encontrando-se mais de metade destes (57) na região Sul, seguido da região Norte (41).

A formação de intensivistas é definida pelo programa formativo aprovado pelo CEMI, conjugada com o Competency-Based Training in Intensive Care Medicine in Europe (CoBaTriCE) e com os protocolos definidos por cada SMI. Tem, por isso, uma componente teórica e prática importante que deve ser monitorizada/avaliada de forma contínua ao longo do período formativo e adaptada a cada instante ao nível do formando.

Neste momento, há nos diversos SMI nacionais 128 internos de formação específica (IFE) de Medicina Intensiva e 111 formandos de via clássica que permitirão no futuro próximo melhorar o panorama deficitário nacional de intensivistas.

A recente situação pandémica pôs a descoberto as deficiências dos SMI que tiveram que aumentar a sua dotação para 1008 camas, o que levaria à necessidade de duplicarmos o número de intensivistas actualmente existentes para podermos assegurar o seu funcionamento. $\mathrm{Na}$ impossibilidade de o fazer, tivemos que recrutar a mão-de-obra necessária para garantir o aumento das solicitações no grupo de internos da formação específica (IFE) de Medicina Intensiva. Ainda assim, muitos dos SMI nacionais associaram internos de ultimo ano ou especialistas de outras especialidades e por vezes intensivistas recém-aposentados, integrando-os na rotina dos SMI, garantindo desse modo a ajuda necessária para realizarem as suas tarefas assistenciais.

Tendo em conta a escassez generalizada de camas e especialistas, o Grupo de Trabalho para Restruturação da Medicina Intensiva recentemente nomeado pela Ministra da Saúde estima propôr um aumento médio do número de camas de Medicina Intensiva (9,5/100 000 habitantes) numa aproximação à média europeia ( 11,5 camas/100 000 habitantes), acrescendo o total actual de camas instaladas em mais um terço.

Este rácio proposto leva à duplicação do número de intensivistas actualmente existentes o que implica a curto prazo, aumentar o número de formandos quer em formação específica (60 meses) quer em via clássica (30 - 36 meses), para poder assegurar a funcionalidade das camas instaladas.

À semelhança da epidemia de pólio de meados do século passado, que pôs a descoberto a escassez de 
recursos e levou à criação da medicina intensiva, esta pandemia que agora vivemos acelerou uma generalidade de processos de organização e de trabalho e espero que sir- va para dotar de forma adequada e realista a capacidade instalada de medicina intensiva nacional, ajustando-a às necessidades.

\section{REFERÊNCIAS}

1. Adhikari NK, Rubenfeld GD. Worldwide demand for critical care. Curr Opin Crit Care. 2011,17:620-25.

2. Halpern NA, Pastores SM. Critical care medicine beds, use, occupancy, and costs in the United States: a methodological review. Crit Care Med. 2015;43:2452-9.

3. Despacho n. ${ }^{\circ}$ 276/1989. Diário da República, II Série, n. ${ }^{\circ} 172$ (1989/07/28). p.7485.

4. European Board of Intensive Care Medicine. Documento Orientador da Formação em Medicina Intensiva - critérios de idoneidade e formação. [consultado 2020 jun 24]. Disponível em: https://ebicm. esicm.org/assets/Upload/National-documents/Portugal/Documentosub-especialidade-20030713.pdf.

5. Lei n. ${ }^{0}$ 117/2015. Diário da República, I Série, n. 1696 (2015/08/31). p.6520-79.

6. Portaria n. ${ }^{\circ} 103 / 2016$. Diário da República, I Série, n. ${ }^{\circ} 79(2016 / 04 / 22)$. p.1380-4.

7. Portaria n. ${ }^{\circ}$ 224-B/2015. Diário da República, I Série, n. ${ }^{\circ} 146$ (2015/07/29). p.5110-(6)-(24).

8. Rhodes A, Ferdinande P, Flaatten Hans, Guidet B, Metnitz P, Moreno R et al. The variability of critical care beds in Europe. Intensive Care Med. 2012;38:1647-53.

9. Colégio de Especialidade de Medicina Intensiva da Ordem dos Médicos. Censo 2020. Lisboa: Ordem dos Médicos; 2020.

10. Vincent JL. Need for intensivists in intensive care units. Lancet. 2000;356:695-6.

11. Ward NS, Afessa B, Kleinpell R, Tisherman S, Ries M, Howell M, et al. Intensivists/Patients ratios in closed ICUs: a statement from the Society of Critical Care Medicine Task Force on ICU staffing. Crit Care Med. 2013;41:638-45

12. Gómez Tello V, Ruiz Morenob J, Weissc M, González Marínd E, Merino de Cose P, Franco Garrobo N, et al. Estimácion de las necessidades profesionales médicos en los servicios de medicina intensiva. Med Intensiva. 2018;42:37-46.

13. Serviço Nacional de Saúde. Rede de Referenciação de Medicina Intensiva. [consultada 2020 jun 24]. Disponível em https://www.sns.gov. pt/wp-content/uploads/2016/11/RRH-Medicina-Intensiva.pdf. 